\title{
BMJ Open Determinants of caregivers' vaccination intention with respect to child age group: a cross-sectional survey in South Korea
}

\author{
Hye-Jin Paek, ${ }^{1}$ Kyung-Ah Shin, ${ }^{2}$ Kisoo Park ${ }^{3}$
}

To cite: Paek H-J, Shin K-Ah, Park K. Determinants of caregivers' vaccination intention with respect to child age group: a cross-sectional survey in South Korea. BMJ Open 2015;5:e008342. doi:10.1136/bmjopen-2015008342

- Prepublication history for this paper is available online. To view these files please visit the journal online (http://dx.doi.org/10.1136/ bmjopen-2015-008342).

Received 1 April 2015

Revised 27 August 2015

Accepted 2 September 2015

CrossMark

${ }^{1}$ Department of Advertising and Public Relations, Hanyang University, Ansan-si, South Korea

${ }^{2}$ National Disaster

Management Institute, Seoul, South Korea

${ }^{3}$ Department of Healthcare Management, Korea

University, Seoul-si, South Korea

Correspondence to Dr Kisoo Park; mediator@korea.kr

\section{ABSTRACT}

Objective: This study examined how knowledge, risk perception, health beliefs and multidimensional health locus of control (HLC) were associated with caregivers' intention to vaccinate their child, and how these associations varied across child age groups.

Setting: South Korea.

Methods: The cross-sectional survey was conducted via a face-to-face interview among 1017 nationally representative caregivers who had children aged 12 or younger. The outcome variable was caregivers' intention to vaccinate their children.

Results: Hierarchical regression analysis indicated that risk perception was negatively associated with vaccination intention only among the age group 4-6 $(\beta=-0.127, p<0.05)$. Perceived benefit was the only significant predictor of the outcome variables for all three age groups. In contrast, perceived barrier was negatively related to vaccination intention only among the age group $7-12(\beta=-0.104, p<0.05)$. Internal HLC was positively related to vaccination intention only among the age group $7-12(\beta=0.151, p<0.001)$, while chance HLC was negatively related to vaccination intention only among the age group $0-3(\beta=-0.121$, $\mathrm{p}<0.05)$.

Conclusions: This study identifies key vaccination intention determinants that are differentially associated with caregivers' children's age groups. To improve vaccination rates, it suggests the need for strategies tailored to children's age.

\section{INTRODUCTION}

Vaccination refers to the administration of a vaccine to boost people's immune system to protect them from various viruses and pathogens. ${ }^{1}$ It is known as a cost-effective method for preventing infectious diseases that are often spread through personal contact and the respiratory organs. Childhood vaccinations in particular are critical for improving the mortality and morbidity of children whose underdeveloped immune systems make them susceptible to infectious diseases.

\section{Strengths and limitations of this study}

- This study is one of the first to identify differential determinants of caregivers' vaccination intention with respect to the child's age group.

- It is one of the first to consider health locus of control as an important predictor of vaccination intention.

- The findings provide specific strategies for public health practitioners to improve vaccination rates.

- Measurement limitations are a low number of items constructing each variable and the reliability of those items.

- The outcome variable was vaccination intention rather than actual vaccination behaviour.

While vaccination has been regarded as one of the most important achievements in the history of public health, ${ }^{2}$ the spread of several infectious diseases still occurs enough to amount to a global health crisis. For example, in 2014, the WHO declared the spread of polio in Africa, South Asia and the Middle East a global health crisis that could result in the failure to globally eradicate one of the world's most serious vaccinepreventable diseases. ${ }^{3}$

Over a short period of time, South Korea has joined the successful countries that have a high vaccination rate and have managed to keep vaccine-preventable infectious diseases at bay. ${ }^{4}$ For example, more than 50000 people caught the measles between 2000 and 2001 , but further spread of that disease was suppressed through vaccinations among 5.8 million people. ${ }^{5}$

As in many other countries, in South Korea the government has implemented various policies to keep the vaccination rate high among children. One policy is the national immunisation program (NIP), which requires newborn babies to have vaccinations for 12 types of infectious disease. ${ }^{6}$ The required 
Table 1 Types and frequency of vaccines required for child age groups

\begin{tabular}{|c|c|c|c|c|}
\hline Disease & Vaccine & Age 0-3 & Age 4-6 & Age 7-12 \\
\hline Tuberculosis & BCG & 1 & & \\
\hline Hepatitis B & Hepatitis B (HepB) & 3 & & \\
\hline Diphtheriae/tetanus/pertussis & Diphtheria, tetanus and acellular pertussis (DTaP) & 4 & 1 & \\
\hline Tetanus and & Tetanus and diphtheria (Td) /Tdap & & & 1 \\
\hline \multicolumn{5}{|l|}{ Diphtheria toxoid (adult type) } \\
\hline Polio & Inactivated polio vaccine (IPV) & 3 & 1 & \\
\hline Haemophilus influenzae type b & Haemophilus influenzae type b (Hib) & 4 & & \\
\hline \multirow[t]{2}{*}{ Streptococcus pneumoniae } & Pneumococcal conjugate vaccine (PCV) & 4 & & \\
\hline & Pneumococcal polysaccharides vaccine (PPSV) & \multicolumn{3}{|c|}{$\begin{array}{l}\text { Only those at a high risk (from } \\
24 \text { months) }\end{array}$} \\
\hline Measles, mumps, rubella & Measles, mumps, and rubella (MMR) & 1 & \multicolumn{2}{|l|}{1} \\
\hline Varicella (chickenpox) & Varicella (Var) & 1 & & \\
\hline Japanese encephalitis & Japanese encephalitis virus (JEV) & 3 & 1 & 1 \\
\hline Influenza & Influenza (flu) & \multicolumn{3}{|c|}{ Every year after 6 months } \\
\hline
\end{tabular}

Source: Standard immunisation schedule on the website by Korean Centers for Disease Control and Prevention. https://nip.cdc.go.kr/irgd/ index.html.

vaccines specific to child age groups are presented in table 1.

Another government-implemented policy checks whether all the children who have newly entered school have received all the required vaccines, and it recommends giving them to those who have not. For this policy to be implemented efficiently, information about all the children newly entered in elementary schools is computerised so that it can be linked to their vaccination information. Additionally, all healthcare institutions are required to register all the vaccination records in the government's online system. Furthermore, according to the Early Childhood Education Act and Infant Care Act, directors in childcare institutions can request vaccination certificates for children newly entering their institutions.

However, despite such government-led efforts, the vaccination rate drops as children get older. The 2012 vaccination survey collected among 6700 caregivers of children up to age 7 found that the vaccination rate for 1-year-old children was $93 \%$, but that it dropped to $80.4 \%$ for 4-year-olds and $60 \%$ for 7 -year-olds. ${ }^{7}$ This finding suggests that caregivers who have children of different ages may have different reasons why they would or would not comply with vaccination requirements. It is therefore critical to understand what factors are differentially associated with these subgroup caregivers' compliance or intention to vaccinate their children.

In some developing countries, improving the vaccination rate might be hampered by lack of access or other environmental considerations in receiving healthcare. ${ }^{2}$ However, in South Korea, this may not be the case because it has a national health insurance system, funded both publicly and privately, under which every South Korean is covered for healthcare and medical treatment. Furthermore, people can freely visit and choose almost any private physician or healthcare facility to which they have access. ${ }^{8}$
If access to a good-quality healthcare system is not the issue, internal factors such as knowledge, perceptions and beliefs may be more important than environmental considerations in determining caregivers' intention to vaccinate their child.

Previous studies have examined factors associated with vaccination or compliance to vaccination in specific contexts such as influenza, ${ }^{9-12}$ pneumonia ${ }^{13}$ and malaria. ${ }^{14}$ A small number of studies have examined caregivers' compliance with childhood vaccination in general. ${ }^{15}$ These have found knowledge, beliefs and attitudes to be predictors of vaccination against infectious disease. These factors are drawn from well-established theoretical frameworks such as the Health Belief Model (HBM) ${ }^{14-17}$ and the Knowledge-Attitude-Practice (KAP) model. ${ }^{18}$ HBM highlights four health belief constructs as important precursors to a health behaviour. The four constructs include perceived susceptibility, perceived severity, perceived benefit and perceived barrier. ${ }^{16}$ Perceived susceptibility refers to people's subjective beliefs about their likelihood of contracting a disease. Perceived severity refers to how serious people believe the disease to be. Perceived benefits refer to people's positive beliefs that the disease can be managed by actions recommended for health. Perceived barriers refer to people's beliefs that a variety of costs (eg, material, psychological) may prevent them from following the recommended behaviour. In addition to the four health belief constructs, self-efficacy was subsequently added to HBM to overcome the model's weak explanatory power. Self-efficacy refers to people's confidence in successfully performing a recommended health behaviour. While knowledge and health beliefs are important determinants of vaccination practice, people's perceptions about risks associated with vaccines have hindered them from getting vaccinations. In fact, one study reported that its participants' flu shot acceptance was negatively associated with the perception that the procedure might 
have side effects. ${ }^{9}$ Anecdotal and population-based evidence shows that caregivers are hesitant to get their children vaccinated due to the potential side effects and the misperception and overestimation of risks associated with vaccination. ${ }^{19}$ Common misperceptions include fatalistic views that children's health and illness may not depend on vaccination. Such views are closely related to the belief that one's health is determined by one's own behaviour, by others or by chance. Such beliefs are collectively referred to as the health locus of control (HLC) ${ }^{20-22}$ Originally drawn from the social learning theory developed by Rotter, ${ }^{23}$ HLC applies that theory's concept of locus of control to health contexts. HLC has evolved as a multidimensional concept that comprises three dimensions: internal HLC (I-HLC), which refers to people's beliefs that their own behaviours exert influences on their health status; powerful others' HLC (P-HLC), which refers to people's belief that health outcomes are dependent on powerful others' (eg, physician, doctors) actions and chance HLC (C-HLC), which refers to people's belief that health outcomes are dependent on chance occurrences, luck and fate. ${ }^{21}$

Previous studies have found a significant relationship between I-HLC, P-HLC, C-HLC and health outcomes; for example, external (P-HLC and C-HLC combined) HLC was positively associated with psychological distress, ${ }^{24}$ whereas I-HLC was linked to positive psychological adjustment. ${ }^{25}$ In the vaccination literature, little research has examined the role of HLC in compliance to vaccination. As an exception, one study reported that, while no significant difference of HLC was found between compliant and non-compliant mothers, mothers tended to have a higher level of external than internal HLC. ${ }^{26}$

On the basis of the existing literature and wellestablished theoretical frameworks, this study examined how knowledge (H1), risk perception (H2) and the five HBM constructs-perceived susceptibility (H3), perceived severity (H4), perceived benefit (H5), perceived barrier (H6) and self-efficacy (H7) - regarding vaccination are differentially associated with caregivers' intention to vaccinate their children. Specifically, we predicted that knowledge, perceived susceptibility, perceived severity, perceived benefit and self-efficacy would be positively related to vaccination intention, while risk perception and perceived barrier would be negatively associated with vaccination intention.

To advance existing knowledge, we included the three HLCs (I-HLC, P-HLC and C-HLC) as potentially important determinants of vaccination intention. However, owing to lack of clear evidence on the associations between each of the HLCs and behavioural intention, we explored these associations as research questions 1-3. Lastly, we further examine how such determinants play differential roles in predicting caregivers' intention to vaccinate their children depending on the children's age (RQ4).

\section{METHODS}

This study analysed data from the 2014 Public Knowledge, Perception, Attitudes, and Practice for Vaccination survey by the Korean Centers for Disease Prevention and Control (CDC). A leading research firm was hired to collect the survey data. The survey was conducted via a face-to-face interview among nationally representative caregivers who had children aged 12 years or younger between 17 June and 4 July 2014. For most research firms, 2 weeks is a typical duration for conducting a survey. The samples were selected using a stratified multistage random sampling method to reflect the proportion of region and age groups based on the 2013 Korean census data. More specifically, a lower level of administrative unit (Gu/Goon) was proportionally allocated to each of the selected 16 cities/provinces nationwide based on the population composition of each region. Within each unit, households with the first child aged 12 or lower were randomly chosen. The parent who was mainly in charge of child vaccination (or caregiving) was asked for an interview. Once the interviewer visited each household, he or she asked who this person was.

\section{Survey instrument and procedure}

Three types of survey questionnaire were administered depending on the age of the participating caregivers' first child. The reason for this procedure is that the required vaccines differ among the three age groups of children, 0-3, 4-6 and 7-12. The survey instrument included a series of questions on the practice of required vaccines, knowledge and risk perceptions, health beliefs and vaccination intention. Some of these items were related to the satisfaction level of the government's current vaccination policy, opinion about the new vaccination policy, and reasons why those who did not vaccinate their children did not do so. These questions were not related to the current study and therefore were not used.

A total of 53 experienced interviewers conducted 1520 face-to-face interviews through door-to-door visits. The interviewers were trained extensively and informed of the purpose of the study and the content of the questionnaire so that they all shared the same level of understanding about the survey. Extensive training and mock interview sessions were also provided to avoid any interviewer bias and to standardise the interview procedure. Before conducting the interviews, interviewers informed the respondents about their rights and assured them about privacy and confidentiality as protected by the Korean Statistics Act. The respondents were informed that the survey's purpose was to understand the public's level of knowledge, perception, attitudes and satisfaction regarding the government's vaccination policies for children. Once the respondents agreed to participate, the interviewers asked them each survey question and recorded their answers. This standardised procedure was intended to avoid any human error due to a mis- 
recording by the interviewer or incomplete responses. A total of 160 questions were asked, and the entire interview took about 30-40 min.

A total of 1017 people participated. The margin of error was $95 \%$ confidence level $\pm 3.1 \%$. The response rate was $25.4 \%$. While this response rate seems low, the following three points secure the sample representativeness and quality: (1) our response rate is relatively higher than the average response rate for national surveys in South Korea, which is $15 \%^{27}$; (2) there is little difference between the sample characteristics and the population characteristics regarding age and region and (3) a low response rate is not necessarily correlated with low quality in a survey's results. ${ }^{28} 29$

Most of the caregivers who participated in the study were females (99.2\%), particularly mothers (98.8\%). About $71 \%$ of the caregivers were in their $30 \mathrm{~s}$, followed by $40 \mathrm{~s}(20.3 \%)$ and $20 \mathrm{~s}(8.4 \%)$. Caregivers with children aged $7-12$ were $45.9 \%(\mathrm{~N}=467)$, followed by those with children aged $0-3$ at $30.7 \%(\mathrm{~N}=312)$, and those with children aged $4-6$ at $23.4 \% \quad(\mathrm{~N}=238)$. The median income bracket was between 3.00 and 3.99 million won per month (approximately US\$3000-US\$3999), and $73.7 \%$ of them had a college degree or higher. The respondents' residence was widely spread out. Detailed demographic information is presented in table 2.

\section{Measures}

The outcome variable in this study is caregivers' intention to vaccinate their children, and the major

\begin{tabular}{lcc}
\multicolumn{3}{c}{ Table 2 Sample characteristics $(\mathrm{n}=1017)$} \\
\hline Gender & $\mathbf{n}$ & Percent \\
Male & 8 & \\
Female & 1009 & 0.8 \\
Age (years) & & 99.2 \\
19-29 & 49 & 4.9 \\
$29-39$ & 758 & 74.5 \\
$40-49$ & 206 & 20.3 \\
$50-59$ & 2 & 0.2 \\
60-69 & 2 & 0.2 \\
Education level & & \\
Middle school graduate & 1 & 0.1 \\
High school graduate & 266 & 26.2 \\
College and above & 750 & 73.8 \\
Monthly householdincome (unit: 10,000 Won) & \\
Under 200 & 12 & 1.2 \\
200-299 & 147 & 14.5 \\
300-399 & 449 & 44.1 \\
400-499 & 279 & 27.4 \\
500-599 & 99 & 9.7 \\
600-699 & 20 & 2.0 \\
Over 700 & 11 & 1.1 \\
Existence of a job & & \\
Yes & 382 & 37.6 \\
No & 635 & 62.4 \\
\hline
\end{tabular}

predictors are vaccination knowledge, risk perceptions, health beliefs and HLC. In addition, on the basis of the existing literature, ${ }^{9}{ }^{11}{ }^{15}$ the following demographic characteristics were considered as determinants for intention to vaccinate: sex, age, marital status, income level and education level.

Vaccination intention was measured with three question items drawn from the existing literature: ${ }^{27}$ 'I will get my child vaccinated on time even if I am busy,' 'I will get my child all the required vaccines,' 'I will get my child vaccines that the government recommends, even if she or he does not like it' (5-point Likert scale with 1=not at all to $5=$ very much). Exploratory factor analysis (EFA) with principal component analysis (PCA) using Varimax rotation resulted in one clear factor with $67.8 \%$ explained. Reliability analysis indicated that $\alpha$ was 0.75 .

Vaccination knowledge was measured with ten 'yes or no' questions drawn from the existing literature, ${ }^{30}$ including the following: 'You can get two vaccinations in a day,' 'If my child has suffered from chickenpox, she or he does not have to get vaccinated again,' 'If you missed the vaccination timeline, you have to get all your vaccinations all over again,' and 'One should get vaccinated for Japanese encephalitis before mosquitos appear in summer.' The knowledge variable was then constructed by counting the 'correct' answers. The knowledge score ranged from 0 (all the questions were answered incorrectly) to 10 (all the questions were answered correctly).

Risk perception was also measured with three question items drawn from the existing literature ${ }^{30}$ : 'I am worried that vaccines are not safe,' 'I am concerned about side effects of vaccination,' and 'One may be more likely to get infected after receiving vaccination' (5-point Likert scale with $1=$ not at all to $5=$ very much). EFA with PCA using Varimax rotation indicated one clear factor with $75.6 \%$ explained. Reliability analysis indicated that $\alpha$ was 0.84 . Thus, the three items were averaged to construct the risk perception variable.

Health beliefs variables included perceived susceptibility, perceived severity, perceived barrier and perceived benefit, all drawn from the HBM. Their measures were drawn from the literature. ${ }^{15}{ }^{30}$ In addition, self-efficacy, as a later-added HBM variable, was also included in the analysis. Owing to lack of survey space, all these variables were measured with two items (5-point Likert scale with $1=$ not at all to $5=$ =ery much), which were averaged to construct each of the variables. The specific question items are as follows. For perceived susceptibility: (1) 'If I don't get my child vaccinated, my child is likely to get an infectious disease'; (2) 'If I don't get my child vaccinated, there is a high possibility that my child may contract an infectious disease.' For perceived severity: (1) 'An infectious disease, which may be contracted due to absence of vaccination, is very serious'; (2) 'My child could die from an infectious disease, which may be contracted without vaccination.' For perceived benefit: (1) 'Vaccination will protect my child from a disease'; (2) 'I believe vaccination will help my child's health.' For 
perceived barrier: (1) 'I don't have enough time to get my child vaccinated'; (2) 'The vaccination fee is a burden for me.' For self-efficacy: (1) 'I can get my child vaccinated on time'; (2) 'It is not difficult for me to get my child vaccinated.'

Drawn from the original multidimensional HLC measurement, ${ }^{21}$ three types of HLC-internal, powerful others and chance HLC-were measured with two items modified to fit the study context. Examples include the following: 'Whether or not my child is healthy depends on how well I can comply with vaccination' (I-HLC); 'Doctors play a major role in preventing my child from getting disease' (P-HLC); and 'No matter what I do, things that hurt my child's health will happen by chance' (C-HLC). Each of these three HLCs were measured by averaging the respective two items (5-point Likert scale with $1=$ not at all to $5=$ very much). Descriptive statistics for the major variables for the pooled sample and three subgroups are presented in table 3 .

\section{Statistical analysis}

To examine significant determinants of vaccination intention, hierarchical multiple regression analysis was performed, first for the entire sample and then for the three subgroups according to the child's age. Prior to performance, assumptions that are required to perform the linear regression analysis-such as multivariate normality, outlier and multicollinearity-were checked and confirmed. ${ }^{31}$

In the models, demographic characteristics such as gender, age, education, monthly household income and employment status were entered in the first block for control purposes. In the second block, knowledge and risk perception variables were entered. HBM variables were included in the third block, and I-HLC, P-HLC and C-HLC variables were included in the final block.
The reason why these variables were entered separately is to investigate how each contributes to explaining the variance of vaccination intention. Results are presented in tables 4 and 5 .

\section{Post hoc power analysis}

We conducted post hoc power analyses using the software package GPower3 to assess whether the statistical tests in this study can guard against type II error. ${ }^{32}$ Power was assessed in multiple regression using $\alpha$ level (0.05), number of predictors (15), sample sizes (both pooled sample and three subgroups) and predetermined effect sizes. In accordance with Cohen (1988, chapter 9), the weak, medium and large effect sizes (f2) are predetermined as $0.02,0.15$ and 0.35 , respectively. ${ }^{33}$ Our results show the following: for the pooled-sample $(\mathrm{N}=1017), \mathrm{f} 2=0.02$, power $=0.83$; $\mathrm{f} 2=0.15$, power $=1.0$; $\mathrm{f} 2=0.35$, power $=1.0$; for the child age $0-3$ subgroup sample $(\mathrm{N}=312), \mathrm{f} 2=0.02$, power $=.27$; $\mathrm{f} 2=0.15$, power $=$ in excess of 0.99 ; $\mathrm{f} 2=0.35$, power $=1.0$; for the child age $4-6$ subgroup sample $(\mathrm{N}=238), \mathrm{f} 2=0.02$, power $=0.20 ; \mathrm{f} 2=0.15$, power $=0.98$; $f 2=0.35$, power $=1.0$; for the child age $7-12$ subgroup sample $(\mathrm{N}=467), \mathrm{f} 2=0.02$, power $=0.42$; $\mathrm{f} 2=0.15$, power $=\mathrm{in}$ excess of 0.99 ; $\mathrm{f} 2=0.35$, power $=1.0$. Following Cohen's 0.80 cut-off criterion of statistical power, our study seems to have more than adequate statistical power to detect moderate and large effects, while our regression models for the subgroups have a weak statistical power to detect small effects.

\section{RESULTS}

\section{Hypotheses 1 and 2: knowledge and risk perception}

Hypotheses 1 and 2 predicted knowledge and risk perception as significant predictors of behavioural intention regarding child vaccination. As shown in table 4, the regression results show that both hypotheses were supported. The less the caregivers perceived risks

Table 3 Descriptive statistics for the major variables for the pooled-sample and three child age groups

\begin{tabular}{|c|c|c|c|c|c|c|c|c|}
\hline & \multicolumn{2}{|c|}{ Age $0-3(n=312)$} & \multicolumn{2}{|c|}{ Age $4-6(n=238)$} & \multicolumn{2}{|c|}{$\begin{array}{l}\text { Age 7-12 } \\
(n=467)\end{array}$} & \multicolumn{2}{|c|}{ Total $(n=1017)$} \\
\hline & Mean (M) & SD & $\bar{M}$ & SD & $\overline{\mathbf{M}}$ & SD & $\mathbf{M}$ & SD \\
\hline Knowledge & 7.26 & 1.44 & 7.24 & 1.46 & 7.17 & 1.50 & 7.21 & 1.47 \\
\hline Risk perception & 3.10 & 0.93 & 3.06 & 0.98 & 3.06 & 0.93 & 3.07 & 0.94 \\
\hline \multicolumn{9}{|l|}{ Health beliefs } \\
\hline Susceptibility & 4.17 & 0.52 & 4.10 & 0.56 & 4.11 & 0.50 & 4.13 & 0.52 \\
\hline Severity & 3.95 & 0.68 & 3.99 & 0.64 & 3.95 & 0.62 & 3.96 & 0.64 \\
\hline Barrier & 3.19 & 0.84 & 3.28 & 0.87 & 3.19 & 0.83 & 3.21 & 0.84 \\
\hline Benefit & 4.23 & 0.52 & 4.17 & 0.52 & 4.18 & 0.57 & 4.20 & 0.55 \\
\hline Self-efficacy & 4.12 & 0.63 & 4.13 & 0.60 & 4.07 & 0.61 & 4.10 & 0.62 \\
\hline \multicolumn{9}{|c|}{ Health locus of control (HLC) } \\
\hline Internal HLC & 4.00 & 0.53 & 3.91 & 0.60 & 3.91 & 0.59 & 3.94 & 0.57 \\
\hline External HLC & 3.69 & 0.68 & 3.72 & 0.67 & 3.67 & 0.64 & 3.69 & 0.66 \\
\hline Chance of HLC & 3.63 & 0.65 & 3.66 & 0.66 & 3.62 & 0.66 & 3.63 & 0.66 \\
\hline Behaviour intention & $4.37^{\star}$ & 0.49 & $4.29^{*}$ & 0.51 & $4.26^{*}$ & 0.53 & $4.30^{*}$ & 0.52 \\
\hline
\end{tabular}


Table 4 Pooled-sample hierarchical linear regression analysis $(n=1017)$

\begin{tabular}{|c|c|}
\hline Variables & $\beta \dagger$ \\
\hline \multicolumn{2}{|l|}{ Block 1: control variables } \\
\hline Gender & -0.013 \\
\hline Age & -0.043 \\
\hline Education & $0.117^{\star \star *}$ \\
\hline Monthly household income & 0.010 \\
\hline Existence of a job & -0.040 \\
\hline$\Delta \mathrm{R}^{2}$ & $0.031^{\star * *}$ \\
\hline \multicolumn{2}{|c|}{ Block 2: knowledge and perception } \\
\hline Risk perception & $-0.080^{\star *}$ \\
\hline Knowledge & $0.074^{\star *}$ \\
\hline$\Delta \mathrm{R}^{2}$ & $0.042^{\star \star \star}$ \\
\hline \multicolumn{2}{|l|}{ Block 3: health beliefs } \\
\hline Susceptibility & $0.076^{\star}$ \\
\hline Severity & 0.041 \\
\hline Barrier & $-0.064^{\star}$ \\
\hline Benefit & $0.254^{* * *}$ \\
\hline Self-efficacy & $0.172^{\star \star \star}$ \\
\hline$\Delta \mathrm{R}^{2}$ & $0.185^{\star \star \star}$ \\
\hline \multicolumn{2}{|c|}{ Block 4: health locus of control (HLC) } \\
\hline Internal HLC & $0.110^{\star * *}$ \\
\hline External HLC & -0.033 \\
\hline Chance of HLC & $-0.065^{\star}$ \\
\hline$\Delta \mathrm{R}^{2}$ & $0.012^{* * *}$ \\
\hline Total $\mathrm{R}^{2}$ & $0.270^{\star \star \star}$ \\
\hline
\end{tabular}

$(\beta=-0.080, p<0.01)$ and know $(\beta=0.074, p<0.01)$ about vaccination, the more likely they intended to get vaccinations for their child.

\section{Hypotheses 3-7: HBM constructs}

Hypotheses 3-7 predicted the relationships between each of the HBM constructs and behavioural intention. Perceived susceptibility $(\beta=0.076, p<0.05)$, self-efficacy $(\beta=0.172, \quad p<0.001)$ and perceived benefit $(\beta=0.254$, $\mathrm{p}<0.001$ ) were significantly and positively associated with vaccination intention, supporting hypotheses 3,6 and 7. In contrast, perceived barrier $(\beta=-0.064, \mathrm{p}<0.05)$ was negatively associated with vaccination intention, supporting hypothesis 5 . However, perceived severity was not significantly related to behavioural intention, which means that hypothesis 4 was not supported.

\section{Research questions 1-3: HLC}

Since little research has examined the role of HLC in vaccination compliance, we explored as research questions the roles of internal, powerful others and chance HLC (I-HLC, P-HLC and C-HLC, respectively) in predicting behavioural intention. The regression results indicate that I-HLC was positively $(\beta=.110, \mathrm{p}<0.001)$ and C-HLC was negatively $(\beta=-0.065, p<0.05)$ associated with vaccination intention. P-HLC was not significantly related to vaccination intention.
Table 5 Comparison of hierarchical linear regression analysis by three child age groups $\dagger$

\begin{tabular}{|c|c|c|c|}
\hline Predictors & $\begin{array}{l}\text { Age 0-3 } \\
(n=312)\end{array}$ & $\begin{array}{l}\text { Age 4-6 } \\
(n=238)\end{array}$ & $\begin{array}{l}\text { Age } 7-12 \\
(n=467)\end{array}$ \\
\hline \multicolumn{4}{|l|}{ Block 1: demographics } \\
\hline Gender & -0.017 & -0.027 & -0.020 \\
\hline Age & -0.089 & 0.054 & -0.010 \\
\hline Education & 0.089 & $0.123^{*}$ & $0.123^{\star \star}$ \\
\hline $\begin{array}{l}\text { Monthly } \\
\text { household income }\end{array}$ & 0.005 & 0.006 & 0.020 \\
\hline Existence of a job & 0.024 & -0.009 & -0.080 \\
\hline$\Delta \mathrm{R}^{2}$ & 0.027 & 0.033 & $0.041^{\star \star}$ \\
\hline \multicolumn{4}{|c|}{ Block 2: knowledge and perceptions } \\
\hline Risk perception & -0.088 & $-0.127^{\star}$ & -0.046 \\
\hline Knowledge & 0.059 & 0.092 & 0.077 \\
\hline$\Delta \mathrm{R}^{2}$ & $0.036^{\star *}$ & $0.084^{\star * *}$ & $0.027^{* * *}$ \\
\hline \multicolumn{4}{|l|}{ Block 3: health beliefs } \\
\hline Susceptibility & 0.053 & $0.138^{*}$ & 0.045 \\
\hline Severity & 0.072 & 0.007 & 0.045 \\
\hline Barrier & -0.073 & 0.012 & $-0.104^{\star}$ \\
\hline Benefit & $0.359^{\star \star \star}$ & $0.261^{\star \star \star}$ & $0.197^{\star \star \star}$ \\
\hline Self-efficacy & 0.095 & $0.193^{\star \star}$ & $0.198^{\star \star \star}$ \\
\hline$\Delta \mathrm{R}^{2}$ & $0.204^{\star * *}$ & $0.192^{\star \star \star}$ & $0.180^{\star \star *}$ \\
\hline \multicolumn{4}{|c|}{ Block 4: health locus of control (HLC) } \\
\hline Internal HLC & 0.035 & 0.073 & $0.151^{* * *}$ \\
\hline External HLC & -0.040 & 0.007 & -0.043 \\
\hline Chance of HLC & $-0.121^{\star}$ & -0.090 & -0.027 \\
\hline$\Delta \mathrm{R}^{2}$ & 0.015 & 0.010 & $0.017^{\star}$ \\
\hline Total $\mathrm{R}^{2}$ & $0.282^{\star * \star}$ & $0.319^{\star \star \star}$ & $0.266^{\star \star *}$ \\
\hline
\end{tabular}

${ }^{*} p \leq 0.05 ;{ }^{* *} p \leq 0.01 ;{ }^{* * *} p \leq 0.001$

†Numbers in the cells are standardised $\beta$ from the final equation. Incremental $\mathrm{R}^{2}$ for each block of predictors is taken at the stage of the block's entry.

Research question 4: differential roles of the predictors by subgroups

Research question 4 explored how such determinants play a differential role in predicting caregivers' intention to vaccinate their children depending on the children's age. As shown in table 5 , some significant associations between the predictors and the outcome variable show different patterns across child age groups. First, education was positively associated with vaccination intention among the age groups $4-6(\beta=0.123, \mathrm{p}<0.05)$ and $7-12$ $(\beta=0.123, p<0.01)$, but not among the age group $0-3$. Risk perception was negatively associated with vaccination intention only among the age group 4-6 $(\beta=-0.127, p<0.05)$. Among the HBM variables, perceived benefit was the only one that significantly predicted the outcome variables for all three subgroups. By contrast, perceived susceptibility was significantly and positively related to vaccination intention only among the age group 4-6 $(\beta=0.138, \mathrm{p}<0.05)$, while perceived barrier was significantly and negatively related to vaccination intention only among the age group 7-12 ( $\beta=$ $-0.104, \mathrm{p}<0.05)$. Self-efficacy, the caregivers' confidence that they can get their child vaccinated in time, was significantly and positively associated with vaccination intention among the age groups $4-6(\beta=0.193, \mathrm{p}<0.01)$ 
and $7-12 \quad(\beta=0.198, \mathrm{p}<0.001)$, but not among the age group 0-3. Lastly, among the HLC variables, I-HLC was positively related to vaccination intention only among the age group 7-12 $(\beta=0.151, p<0.001)$, while C-HLC was negatively related to vaccination intention only among the age group $0-3(\beta=-0.121, \mathrm{p}<0.05)$.

Overall, the regression model for the entire sample explained $27 \%$ of total variance in vaccination intention. Among the three subgroups, the model for the age group 4-6 explained the most $(31.9 \%)$, while that for the age group 7-12 explained the least (26.6\%).

\section{DISCUSSION}

The purpose of this study was to identify what factors are associated with caregivers' vaccination intention for their children in South Korea, and how these associations vary across three child age groups.

We found that the caregivers with children aged 7-12 have a significantly lower level of vaccination intention than those with children aged 0-3. This finding seems to coincide with the Korean CDC report that the vaccination rate drops as children become older. ${ }^{4}$ There may be a few reasons for this drop. While caregivers, mostly mothers, may have initially complied with their doctors to protect their newborn babies from various diseases, they now may have either children who are healthy or children who became ill regardless of vaccination. Moreover, in their everyday lives, they may have agendas that are more pressing than learning about required or suggested vaccines. Indeed, according to a Korean study examining media use patterns of caregivers, ${ }^{34}$ parents reported that, to learn information on childcare, they use personal and social media the most $(59 \%)$, followed by families and friends (20\%) and government/educational institution (16.4\%). Parents also reported that, among various personal and social media, they use childcare-related portal sites the most (58.8\%), followed by childcare-related online communities $(26.2 \%)$. This study's results imply that caregivers may rely more on direct or indirect personal experiences than on government policy or experts' opinion.

While this reasoning is only speculative and definite answers are beyond the scope of this study, more important questions may be what factors are differentially associated with vaccination intention among caregivers whose children's ages differ. In a result consistent with a previous study, ${ }^{9}$ risk perception was a significant determinant of vaccination intention among all the participants. However, the subgroup analysis shows a more nuanced pattern which that study did not capture: risk perception was negatively associated with vaccination intention only among the age group 4-6. This could mean that the other age groups may have more important factors associated with vaccination intention. In particular, caregivers of newborn babies ( $0-3$ years) may just follow whatever doctors tell them to do for their baby. As long as they believe that vaccination is beneficial (perceived benefit), and they do not think that their child's health is completely up to chance (negative role of C-HLC), they may generally intend to get their child vaccinated. However, as the child gets older, they may hear more about the side effects or risks associated with vaccination, which may lower their intention to get their child vaccinated. Also, caregivers may face more pressing everyday concerns that prevent them getting from their child vaccinated, such as time and cost. Among caregivers with children aged 7-12, the perceived barrier was found to be a significantly negative predictor of vaccination intention. In addition, their confidence and locus of control with respect to managing their child's health are also significantly positive predictors of vaccination intention. This finding seems to point to a need for more target-specific policy and education/communication strategies to improve the vaccination rate.

In general, another finding consistent with existing studies was that health beliefs seemed to play a much stronger role than knowledge in predicting vaccination intention. ${ }^{14}{ }^{15}$ Moreover, as other studies suggest, HLC is also a significant predictor. ${ }^{22} 24{ }^{25}$ However, the significance of the role played by HLC differed among the age groups in terms of its types and its explanatory power. That is, the HLC block in the regression model significantly explained vaccination intention only among the caregivers with children aged $7-12$. Since not much vaccination research ${ }^{26}$ has been done on the predictive role of HLC, future studies should pay more attention to this variable and try to replicate our findings.

Most of this study's limitations are related to measurement. First, owing to space limitations in the survey, it was not possible to ask an extensive list of question items for each variable. As a result, most of the predictors were constructed with only two question items. Future research should try to include a greater number. Second, the respective items had a relatively low reliability. This result is puzzling because these items were drawn from existing scales ${ }^{52} 2130$ to secure content and construct validity. While many explanations for such low reliability are possible, one plausible explanation may be that some of the variables may be not one-dimensional but rather multidimensional. For example, the perceived barrier and benefit questions can vary across contexts, which could cover an array of aspects such as psychological, physical (eg, access, distance), economic (eg, cost) and social (eg, dislike doctors). However, the items we used covered only a few aspects. A related issue is that the parents' decision about child vaccinations is multifactorial, involving knowledge, risk perception, health beliefs and locus of control, as well as emotions and trust in the government's and healthcare professionals' recommendations. Future research should cover the various aspects of perceived barriers and benefits and find out which may be more important than others in determining vaccination practice.

Third, our survey had a response rate of $25.4 \%$, which is low by Western standards. Although we explained earlier 
why our sample still secures its representativeness and quality, a higher response rate would secure even greater representativeness and generalisability. Survey studies in Korea generally suffer from a low response rate, but future research should make more efforts to improve it.

\section{CONCLUSION/RECOMIMENDATION}

Despite these limitations, this study contributes to existing vaccination literature both theoretically and practically. Theoretically, it highlights the importance of identifying different factors associated with caregivers' children's age groups. In addition, it shows that the roles of HLC deserve more attention and need to be considered as important determinants of vaccination intention. Practically, this study suggests that different health communication strategies may be necessary for caregivers depending on their children's ages. For caregivers with children aged $0-3$, the obstetricians and paediatricians with whom they have direct contact may play a critical role in informing them about the importance and benefits of vaccination. For the caregivers with children aged 4-6, communication and education efforts via various media may be needed to reduce possible misperceptions and overestimations of vaccination risks. For the caregivers with older children aged 7-12, perceived and actual barriers to vaccination intention should be removed, for example by providing more specific action reminders for vaccination, and by implementing a policy that makes various vaccines free and affordable. Such tailored and targeted communication and vaccination practice strategies could lead to more successful protection of children from vaccine-preventable diseases.

Acknowledgements The authors would like to acknowledge the Korea Centre for Disease Control and Prevention (KCDC) to allow us to analyse the survey data.

Contributors H-JP designed the study, established the method and questionnaire, and developed the paper. K-AS contributed to developing the questionnaire, wrote the methods section and analysed the data. KP provided insights on measurement and contributed to conceiving the argument and writing the paper.

Competing interests None declared.

Ethics approval The study protocol was approved by the Internal Review Board of the Korea Centers for Disease Control and Prevention.

Provenance and peer review Not commissioned; externally peer reviewed.

Data sharing statement The data set, survey measures and statistical code are available from the corresponding author on request.

Open Access This is an Open Access article distributed in accordance with the Creative Commons Attribution Non Commercial (CC BY-NC 4.0) license, which permits others to distribute, remix, adapt, build upon this work noncommercially, and license their derivative works on different terms, provided the original work is properly cited and the use is non-commercial. See: http:// creativecommons.org/licenses/by-nc/4.0/

\section{REFERENCES}

1. WHO. Health topics: immunization. http://www.who.int/topics/ immunization/en/ (accessed 20 Jan 2014).
2. $\mathrm{Hu} \mathrm{Y}, \mathrm{Chen} \mathrm{E}, \mathrm{Li} \mathrm{Q}$, et al. Immunization coverage and its determinants among children born in 2008-2009 by questionnaire survey in Zhejiang, China. Asia Pac J Public Health 2015;27: NP1132-43.

3. BBC. World facing polio health emergency. Published 5 May 2014. http://www.bbc.com/news/world-27284389

4. Korea Center for Disease Control and Prevention. 2013 Korea national immunization survey. http://www.cdc.go.kr/CDC/contents/ CdcKrContentView.jsp?cid=27222\&memenul=HOME001MNU1130-MNU1765-MNU1819 (accessed $10 \mathrm{Jul} 2014$ ).

5. Korea Center for Disease Control and Prevention. The information of vaccination tommorrow. https://nip.cdc.go.kr/irgd/reference/leaflet/ vacc\%20tomorrow/vacc\%20tomotomo/EBook.htm (accessed 29 Nov 2011).

6. Lee JK, Choi WS. Immunization policy in Korea. Infect Chemother 2008;40:14-23.

7. Korea Center for Disease Control and Prevention. Knowing immunization. http://blog.naver.com/kcdc allthat/80198629142 (accessed 25 Sep 2013).

8. Kim J, Kim TH, Park E-C, et al. Factors influencing unmet need for health care services in Korea. Asia Pac J Public Health 2015;27: NP2555-69.

9. Chapman GB, Coups EJ. Predictors of influenza vaccine acceptance among healthy adults. Prev Med 1999;29:249-62.

10. Chi R-C, Neuzil KM. The association of sociodemographic factors and patient attitudes on influenza vaccination rates in older person Am J Med Sci 2004;327:113-17.

11. Mok E, Yeung SH, Chan MF. Prevalence of influenza vaccination and correlates of intention to be vaccinated among Hong Kong Chinese. Public Health Nur 2006;23:506-15.

12. Cho H-S. Factors associated with influenza vaccination behavior among high-risk adults. J Korean Soc Health Educ Promot 2002;19:127-38.

13. Schneeberg A, Bettinger JA, McNeil S, et al. Knowledge, attitudes, beliefs and behaviours of older adults about pneumococcal immunization, a Public health agency of Canada/Canadian institutes of health research Influenza Research Network(PCIRN) investigation. BMC Public Health 2014;14:442.

14. Farquharson L, Nobel LM, Barker C, et al. Health beliefs and communication in the travel clinic consultation as predictors of adherence to malaria chemoprophylaxis. Br J Health Psychol 2004:9:201-17.

15. Tuma JN, Smith SM, Kirk RH, et al. Beliefs and attitudes of caregivers toward compliance with childhood immunizations in Cameroon. Public Health 2002;116:55-61.

16. Janz NK, Becker MH. The health belief model: a decade later. Health Educ Q 1984;11:1-47.

17. Carpenter CJ. A Meta-analysis of the effectiveness of health belief model variables in predicting behavior. Health Comm 2010;25:661-9.

18. Kim G-H, Lee H-Y, Cho S-I. Knowledge and practice of influenza vaccination among health workers and teachers. Korean Public Health Res 2004;30:1-12.

19. Opel DJ, Diekema DS, Lee NR, et al. Social marketing as a strategy to increase immunization rate. Arch Pediatr Adolesc Med 2009;163:432-7.

20. Wallston KA, Wallston BS. Who is responsible for your health? The construct of health locus of control. In: Sanders GS, Suls J, editors. Social Psychology of Health and IIIness 1989:65-95.

21. Wallston KA, Wallston BS, DeVellis R. Development of the Multidimensional Health Locus of Control (MHLC) scale. Health Educ Behav 1978;6:160-70.

22. Wallston KA. The validity of the multidimensional health locus of control scales. J Health Psych 2005;10:623-31.

23. Rotter JB. Social learning and clinical psychology. Englewood Cliffs, NJ: Prentice-Hall, 1966.

24. Wu AMS, Tang CSK, Kwok TCY. Self-efficacy, health locus of control, and psychological distress in elderly Chinese women with chronic illnesses. Aging Ment Health 2004;8:21-8.

25. Takakura M, Sakihara S. Psychsocial correlates of depressive symptoms among Japanese high school students. J Adolescent Health 2001;28:82-9.

26. Rosenblum EH, Stone EJ, Skipper BE. Maternal compliance in immunization of preschoolers as related to health locus of control, health value, and perceived vulnerability. Nurs Res 1981;30: 337-42.

27. Min KA, Park EY. National statistics response rate. Seoul, South Korea: Statistical Research Institute; 2012

28. Keeter S, Kennedy C, Dimock M, et al. Gauging the impact of growing nonresponse on estimates from a national RDD telephone survey. Public Opinion Q 2006;70:759-79. 
29. Visser PS, Krosnick JA, Marquette J, et al. Mail surveys for election forecasting? An evaluation of the Columbia Dispatch Poll. Public Opinion Q 1996;60:181-227.

30. Lee H, Kim D. The effects of media types and audience profiles on public's knowledge, attitude, and behavioral intention toward immunization. Korean J Ad PR 2011;13:326-60.

31. Cohen J, Cohen P, West SG, et al. Applied multiple regression/correlation analysis for the behavioral sciences. 3rd edn. Routledge, 2002.
32. Cohen J. Statistical power analysis for the behavioral sciences. 2nd edn. Hillsdale, NJ: Erbaum, 1988.

33. Faul F, Erdfelder E, Lang A-G, et al. G*Power 3: a flexible statistical power analysis program for the social, behavioral, and biomedical sciences. Behav Res Methods 2007;39:175-91.

34. Min J. An analysis on parents' using child caring information and measures to increase the availability. Korea Inst Child Care Edu 2014;42:16-26. 